\title{
On the Relationship between Iranian EFL Teachers' Cognitive Flexibility and Iranian EFL Learners' Attitudes towards English Language Learning
}

\author{
Marhamat Saffarin (M.A.) \\ English Department, Islamic Azad University, Torbat-e Heydarieh Branch, Iran \\ Saffarin.m@gmail.com/Marhamatsaffarin@yahoo.com
}

Mohammad Ali Fatemi (PhD, Associate Professor)

English Department, Islamic Azad University, Torbat-e Heydarieh Branch, Iran; m.a.fatemi94@gmail.com

\author{
Doi:10.5901/mjss.2015.v6n6s1p34
}

\section{Abstract}

It is believed that EFL learners' positive attitudes highly influence their language success. Students' negative attitudes can be replaced by positive ones and this is partly the art and duty of the teachers. Accordingly, there is a need for EFL teachers to try to promote their students' positive attitudes. Different factors including EFL teachers' characteristics contribute to the development of EFL learners' positive attitudes. This study explored the relationship between Iranian EFL teachers' cognitive flexibility and Iranian EFL learners' attitudes towards English language learning. To achieve this aim, a sample of 357 Iranian EFL teachers and 1785 Iranian EFL learners participated for gathering the data. To measure EFL teachers' cognitive flexibility and EFL learners' attitudes as demanded for the study, Iranian EFL teachers filled out Cognitive Flexibility Scale and Iranian EFL learners completed Attitude towards English Language Learning Questionnaire in terms of Behavioral, Cognitive and Emotional aspects. For data analysis Pearson Product-Moment Correlation was run. The results showed a significant relationship between Iranian EFL teacher's CF and their students' attitudes towards English language learning. The results of this study can provide hints for all those who involve in EFL teaching and learning to think about how to integrate CF into EFL educational policy as well as how to promote it as a vital mental capability in EFL teachers and learners.

Keywords: cognitive flexibility, attitude

\section{Introduction}

Teachers play a key role in SL/FL learning. Their characteristics along with other factors determine their effectiveness and the impact they have on students' attitudes and achievement. According to Stronge (2007), being not only planned but also flexible and spontaneous when necessary to be responsive to situations and students' needs is one of the teacher-related features that contribute directly to effective teaching.

Teimourtash (2013) states language teaching and learning are dynamic processes. In every moment of a language class, some unpredictable situations may happen which may facilitate teaching and learning processes or vice versa. He believes teachers should be informative and flexible immediately to manage these unexpected situations appropriately to obtain the right goal.

Parks (1994) stated that every person who wants to be flexible in various educational and social circumstances, he is required to be cognitively flexible. Spiro and Jehng (1990:165) defined cognitive flexibility (CF) as "The ability to spontaneously restructure one's knowledge, in many ways, in adaptive response to radically changing situational demands. This is a function of both the way knowledge is represented and the processes that operate on those mental representations." Martin and Rubin (1995) defined cognitive flexibility as individuals' (a) understanding of the fact that in every presented context there are available alternatives, (b) tendency to change, adapt to the situation and be flexible and (c) self-efficacy to believe about their capacity to be flexible.

Zainol Abidin, Pour-Mohammadi, and Alzwari (2012) stated that attitudes play a crucial role in language learning and highly affect learners' failure or achievement. According to Gardner (1985), positive attitudes can have beneficial effects on learning by enhancing students' motivation and leading them to achieve educational goals. But negative attitudes affect negatively and hinder students' language achievement. Tabatabaei and Bandari (2012) define attitude as a psychological concept which determines individuals' amount of dislike or like of something. In language learning, learners' attitudes are language learners' perceptions of second or foreign language and other factors associated with 
them.

Wenden (1991, as cited in Soleimani and Hanafi 2013, Zainol Abidin et al., 2012 and Al-Tamimi and Shuib, 2009) stated three components for attitudes, namely behavioral, cognitive and affective. According to him, behavioral dimension includes behavioral objectives or actions in relation with attitude object. Opinions and viewpoints towards attitude object are the basic constituents of cognitive section. Ultimately, affective component of attitude deals with likes, dislikes, and feelings towards attitude subject.

This study aimed to find the relationship between Iranian EFL teachers' cognitive flexibility and Iranian EFL learners' attitudes in terms of behavioral, cognitive and emotional aspects whose important roles shouldn't be underestimated in language teaching and learning.

\section{Review of Literature}

\subsection{Teacher Flexibility}

Flexibility is a thought-related skill focusing on an individual's ability to change strategies to adapt to novel situations and cope with various situational challenges.

Teimourtash (2013) believes that teachers' flexibility can be applied to all teaching settings. It is related to teachers' awareness. He says implementing flexibility spectrum, all required things acting as shortcut to improve learners' comprehension of the use of the desired language, can facilitate language learners' achievement.

\subsection{Cognitive Flexibility}

According to Dennis \& Vander Wal (2010), although researchers conducted several studies, there is no generally accepted opinion about measurement and definition of CF construct. Generally speaking, the capability to change cognitive sets to adjust them to changing environmental stimuli is the central part of most operational definitions of CF.

Carvalho and Moreira (2005) defined CF as a switch in thought based on a requirement to switch one's previous thoughts to novel situations. It contains considering multiple aspects of thinking simultaneously. They mentioned other names for CF including, attention switching, task shifting, mental set or cognitive shifting and mental flexibility. Elen, Stahl, Bromme and Clarebout (2011) defined CF as individuals' considering choices in mindful and balanced ways. They said CF is observable when someone can adapt to situational changes, finds alternatives, searches new information, is willing to change, work with ideas tentatively, and adapt to new situations. They stated that cognitively flexible individuals automatically think deeply and adaptively instead of mindless, routine answers to fixed situations.

According to Deak (2003), CF is dynamic modification, construction and activation of cognitive processes based on linguistic and nonlinguistic environmental data in response to changing task demands. While changing situational factors, cognitive system can adjust to new context through shifting attention, choosing relevant data to select forthcoming answers, making plans and creating novel activation conditions to feed back into the situation.

Generally speaking, CF is a higher-order cognitive ability that enables individuals to adapt responses to changing unpredictable situational demands by choosing task-related data. It's related to controlled shifts in cognitive activity over time, tasks, or problems. Deak (2003) asserted that CF is required for language processing because most of language learners or teachers don't face completely predictable linguistic situations and learning-teaching environments, or use only learned sequences to teach and learn words and sentences. They encounter unpredictable circumstances for which $\mathrm{CF}$ is required to cope with novel problems.

\subsection{Cognitive Flexibility Theory (CFT) and Cognitive Flexibility Hypertexts (CFHS)}

Spiro, Vispoel, Schmitz, Samarapungavan \& Boerger (1987) suggested cognitive flexibility theory, a constructivist theory of instruction and learning. Its goal is to reduce learners' problems while acquiring advanced levels of knowledge. Spiro, Feltovich, Jacobson \& Coulson (1992: 65) mentioned, "Central claim of CFT is that revisiting the same material, at different times, in rearranged contexts, for various purposes, and from different conceptual perspectives is essential for attaining the goals of advanced knowledge acquisition".

Spiro, Coulson, Feltovich, \& Anderson (1988) stated CFT principles which were also mentioned by Moreira (1999) and Carvalho \& Moreira (2005). Based on them, oversimplification of knowledge is avoided, multiple knowledge representations should be contextualized in learning tasks, teaching materials should be context-sensitive, complexity should be introduced at early learning stages, case-based instruction is emphasized, knowledge construction is focused 
not mere information transmission, advanced knowledge acquisition must happen in real-world contexts and highly interconnecting knowledge sources should be used instead of compartmentalized sources.

CFT introduce a different view to knowledge acquisition and instruction through the use of interactive technology which provide multifaceted case-based representations of conceptual complexity, interrelatedness and overlap. Spiro et al. (1988) stated that via cases which play the role of context-based knowledge examples, information should be provided from diverse intellectual perspectives which facilitate its acquisition and transference to new situations. Accordingly, hypertext/hypermedia is considered the best means to facilitate navigating through complicated domains of information and provide non-linear links which help implement multiple dimensions of representing knowledge and develop CF.

Carvalho and Moreira (2005) stated that because CFT's focus is on representing the same teaching materials repeatedly from diverse perspectives in rearranged instructional sequences, they are better to be presented via CFHs which follow a case-based approach. CFHs enable learners to involve in activities which are cognitively manageable for the aim of reducing the willingness to oversimplify learning problems. Following this, Moreira (1999) stated that CFH is an effective medium for making the learners capable of implementing and transferring their knowledge to new situations. He mentioned that some samples of CFHs have already been successfully implemented.

\subsection{Implications for Education and General Learning}

Boger-Mehall (1996) stated that individual's capability to simultaneously think about multiple concepts and to switch between different aspects of thought is an integral part of teaching and learning processes which is vital to success. As he mentioned, the fact that the teachers' teaching methods greatly influence the formation and the nature of their learners' cognitive structures which in turn impact learners' capability to store and readily access data shows the important role of teachers' CF in education.

Duffy and Jonassen (1992) stated that enabling individuals to learn as well as appropriately adapt and apply what they learn to novel contexts is an essential goal of every educational system. Therefore, integration of CF into educational policy is recommended. Accordingly, hypertext which is a technology-supported instruction can be considered a means to integrate CF into education.

\subsection{Attitude}

Ajzen $(2005$, p.3) defines attitude as "disposition to respond favorably or unfavorably to an object, person, or event". Gardner (1985) mentioned attitudes are related to people's standards and viewpoints which encourage or discourage the decisions they make in their activities. Richards and Platt (1992) defined language attitude as the attitude which speakers of various languages have towards their own language or other languages. Positive or negative emotional expressions towards a language may reflect impressions of ease or difficulty of learning, linguistic simplicity, degree of importance, language speakers, etc.

Many scholars believed that individuals' language success is highly affected by their attitudes towards the language i.e. how they evaluate the target language, its speakers, culture and learning environment. Brown (2007) said positive attitudes toward self, the native and the target language group increased language proficiency.

Kara (2009) mentioned that language learning is a positive change in the individuals' personality regarding cognitive, emotional and behavioral dimensions. Zainol Abidin et al. (2012) also stated that learning process includes social, psychological and cognitive aspects. Accordingly, behavioral, cognitive and affective dimensions are considered for attitudes each of which is based on a theoretical approach (behaviorism, cognitivism and humanism).

\subsection{Related Studies}

\subsubsection{Studies on Cognitive Flexibility}

Several studies have been performed about different CF-related subjects such as CF itself, CFT, its implementations in educational settings, etc.

In their investigation, Martin and Rubin (1995) found positive relationships between CF and behavioral flexibility while negative relationship between CF and rigidity. Moreover relationships were found between CF and interaction involvement including perceptiveness, responsiveness and attentiveness. They also found that individuals with high CF reported their high self-monitoring and self-efficacy skills.

Martin and Anderson (1998) performed three studies to investigate CF scale validity. In the first study a positive 
correlation was found between CF, responsiveness and assertiveness. In the second, no difference was observed between a person's self-report of CF and his peers' perceptions of his CF. In the third one investigating CF and selfefficacy, those participants with high CF showed more confidence in their capability to achieve communication aims. It was concluded that CF affects individuals' class participation. The results of these studies confirm the idea that communication competence involves $\mathrm{CF}$ as a significant component.

Moreira (1999) performed a study concerning CFT and its application to the construction of learning hypertexts to explore the probability of developing EFL teachers' CF within the area of mistake management. Comparison group was exposed to teaching materials of Mistake Management data-base presented in a linear and traditional way. Experimental group was exposed to the same materials but the data-base followed a flexible, non-linear, and criss-crossed structure for multiple interconnected presentations of the materials based on CFT principles. The experimental group showed higher levels of performance in both far and near transfer problem solving tasks. He concluded that careful thematic indexing of complex knowledge in course materials design and in hypertext learning environments is required for both learners and teachers.

Chesebro and Martin (2003) found that CF was positively related to conversational sensitivity in a way that it can be considered a significant component of conversational sensitivity. It means that conversationally sensitive individuals are informed about their alternatives for directing and managing conversations.

Cayanus (2005) conducted a study to investigate whether affective learning, CF, teacher self-disclosure and student motives to communicate affect students' propensity to ask questions in classroom or not. To this aim, 216 participants completed scales measuring the mentioned variables. It was found that participatory student motive to communicate and CF anticipated student question asking in class.

Martin, Staggers, and Anderson (2011) conducted a study to examine the validity of Cognitive Flexibility Scale developed by Martin and Rubin (1995). Participants completed a questionnaire measuring CF, intellectual flexibility, selfcompassion, dogmatism, and preference for consistency. They found positive relationships between self-compassion, intellectual flexibility and CF. A negative relationship was revealed between CF and dogmatism. Additionally, the findings rejected the hypothesis that predicted a negative relationship between CF and preference for consistency.

\subsubsection{Studies on Attitude}

Hosseini and Pourmandia (2013) state that perception and attitude toward the target language are the two most important factors influencing language learning.

Abdol Latif, Fadzil, Bahroom, Mohamad and Ng (2011) conducted a research to investigate whether motivation, attitude, instrumental orientations and anxiety affected learners' performance in ESL. The results showed significant correlations between learners' performance in English course and all the four variables. Among all, instrumental orientation and attitude positively impacted learners' linguistic performance.

Soleimani and Hanafi (2013) explored medical students' attitudes towards learning English in terms of cognitive, behavioral and emotional aspects as well as gender-related differences in this regard. The results revealed a highly positive attitude in students concerning learning English. However, male students' attitudes were higher than females. The results demand teachers' paying attention to learners' attitudes duo to the great impact they have on learners' language achievement.

Tseng (2013) explored the relationship between EFL students' attitudes toward foreign culture and their English proficiency levels. Related to attitudes, family, ethnic, school and social aspects were considered. 90 students were organized according to their English proficiency level, namely high and low proficiency level. One of the outcomes of this probe was a significant correlation between attitudes toward culture and English proficiency levels of the high-proficiency learners.

Duo to the importance of cognitive flexibility and attitude, these variables were the subject of investigation in this research. Although several researches have been conducted regarding either of these variables independently, no one examined the relationships between teachers' CF and learners' attitudes towards English language learning in an Iranian EFL context. Following other researchers' opinions, the researcher bases the theoretical framework of this study on Cognitive Flexibility Theory suggested by Spiro et al. (1987).

\section{Research Question and Hypothesis}

RQ: Is there any significant relationship between Iranian EFL teachers' cognitive flexibility and Iranian EFL learners' attitudes towards English language learning? 
H0: There is no significant relationship between Iranian EFL teachers' cognitive flexibility and Iranian EFL learners' attitudes towards English language learning.

\section{Research Methodology}

\subsection{Participants and Setting}

To gather the required data, a sample of both Iranian EFL teachers teaching at English institutes and a number of their students participated voluntarily. The sample participants were selected randomly on the basis of the researcher's accessibility. They were mostly from some big provinces of Iran including Tehran, Khorasan Razavi, Khorasan Jonoobi, Lorestan, Kerman and Semnan.

The number of EFL teachers were 357 (182 males and 175 females) having different years of teaching experiences. Additionally, 1785 (630 males and 1155 females) EFL students of the same teachers who studied English at upper-intermediate and advanced levels of language institutes participated in this investigation.

It was estimated that the total number of EFL teachers teaching in different institutes of Iran equals 5000 people (considering 1000 language institutes in Iran with an average of $5 \mathrm{EFL}$ teachers in upper-intermediate and advanced levels for each institute). Regarding this total population, the required sample of participants were about $357 \mathrm{EFL}$ teachers and 1785 EFL learners considering 5 learners for each of teachers of this study. This sample size was calculated using Sample Size Table developed by Krejcie and Morgan (1970). (Considering 95\% of the level of confidence with a Margin of Error of about 5.0\%).

\subsection{Instrumentation}

\subsubsection{Cognitive Flexibility Scale (CFS)}

In this study, Cognitive Flexibility Scale (Martin and Rubin, 1995) was used to measure EFL teachers' CF. It is a selfreport questionnaire consisting of 12 items. Participants were asked to determine their level of agreement with the items using a six-point, Likert-type response scale ranging from 1 (strongly disagree) to 6 (strongly agree).

Internal reliabilities for this scale calculated previously through Cronbach's Alpha have ranged from .81 to .82 (Martin and Anderson, 1998; Martin, Anderson and Thweatt, 1998). Construct and content validity were also indicated by Martin and Anderson (1998). Construct validity was revealed through the relationship between self-efficacy and CF. Content validity was shown through finding high correlations between assertiveness, responsiveness and CF.

To assure CFS reliability in an Iranian EFL context, it was piloted by the researcher and calculated Cronbach's Alpha was 0.866 which shows acceptable degree of reliability.

\subsubsection{Attitudes towards English Language Learning Questionnaire (AELLQ)}

To measure Iranian EFL learners' attitude, Attitudes towards English Language Learning Questionnaire developed by Soleimani and Hanafi (2013) was used. It includes 30 items through which participants were required to choose selectedresponse items along a one (Strongly Disagree) to five (Strongly Agree) Likert scale. This questionnaire considered emotional, behavioral and cognitive aspects of attitudes.

According to Soleimani and Hanafi (2013), reliability of general AELLQ was 0.90 and Cornbach's Alpha values concerning its three aspects were (behavioral $=0.84$; cognitive $=0.71$; emotional $=0.77$ ). The validity of $A E L L Q$ items was also reported to be high.

Reliability of AELLQ (Soleimani and Hanafi, 2013) applied in this study was also calculated by the researcher. Cronbach's alpha of 0.931 was obtained and values concerning its aspects separately were (behavioral $=0.767$; cognitive=0.761; emotional=0.917).

It should be noted that there were some items in CFS and AELLQ which were negatively worded. These items were reverse coded for the purpose of having higher scores indicating greater amount of Cognitive Flexibility and Attitude.

\subsection{Procedure}

To measure the reliability of the questionnaires and their clarity, they were piloted before their administration to the 
sample population. For piloting CFS, it was distributed among 20 randomly selected Iranian EFL teachers who didn't take part in the actual research but their characteristics were similar to the participants. To pilot AELLQ, it was distributed among 20 Iranian EFL learners. The questionnaires' validity in the Iranian EFL context of the present study was also estimated through asking two experts as well as conducting factor analysis. The calculated reliability and validity of the scales revealed that their items were completely appropriate for research goals. The instructions provided by the researcher were also quite lucid to increase the reliability of the responses.

Prior to the distribution of the questionnaires, approval was obtained from the managers of the targeted language institutes. Participants were ascertained that their information would be treated as strictly confidential. They were given an orientation to the research and were asked to fill in the questionnaire items based on what they really were or thought not what they desired to be.

To collect the required data, CFS was responded by Iranian EFL teachers and AELLQ by Iranian EFL learners. The needed time for filling out each questionnaire was about 15 minutes and the questionnaires were completed in class concurrently. In the present study, availability sampling was used. Data collection procedure started at July 2014 and ended at November 2014.

Successive to data collection phase, the data was analyzed by means of SPSS and via running Pearson ProductMoment Correlation Coefficient. Since the aim of the study was to explore about significant relationships between CF and $A E L L$, the researcher compared the results of the questionnaires and correlations between the variables were calculated. To be more specific, both scales and subscales utilized in this study were taken into account.

\subsection{Study Design}

The researcher selected survey method, a method of gathering data from samples who are representative of a whole population, for this quantitative study. The variables were arranged based on correlational and factorial design in which more than one independent variable were involved and the existence or non- existence of the significant relationships between Iranian EFL teachers' CF and their students' attitudes were explored. Correlational designs are considered as a subcategory of ex post facto designs. Therefore, this study followed an ex post facto design, too. For data analysis conducted through SPSS, both descriptive and inferential statistics were applied.

\section{Results and Discussions}

To answer research question raised in this study i.e. whether there is any significant relationship between Iranian EFL teachers' cognitive flexibility and Iranian EFL learners' attitudes towards English language learning in terms of behavioral, cognitive and emotional aspects, the relationships between these variables were assessed using Pearson ProductMoment Correlation formula. Both scales and subscales were taken into account.

First a correlation was run to examine the relationship between EFL teachers' CF and EFL learners' overall attitudes (Table 1). Results of conducting analysis indicated a significant positive correlation between these two variables $(r=.32, p<.05)$. It means the higher Iranian EFL teachers' CF; the more positive attitudes have Iranian EFL learners. Accordingly, the null hypothesis i.e. "there is not any significant relationship between Iranian EFL teachers' CF and Iranian EFL learners' attitudes" is rejected.

Table 1: Pearson Correlations of EFL Teachers' CF and EFL Learners' Attitude (Total)

\begin{tabular}{llcc}
\hline & & total.attitudes & cognitive.flexiblity \\
\hline \multirow{3}{*}{ total.attitudes } & Pearson Correlation & 1 & $.324^{* *}$ \\
& Sig. (2-tailed) & & .000 \\
& $\mathrm{~N}$ & 357 & 357 \\
\multirow{3}{*}{ cognitive.flexiblity } & Pearson Correlation & $.324^{* *}$ & 1 \\
& Sig. (2-tailed) & .000 & 357 \\
\hline
\end{tabular}

**. Correlation is significant at the 0.01 level (2-tailed).

Further analyses were done to examine the correlations between Iranian EFL teachers' CF and subscales of Iranian EFL learners' AELL. First, the correlation between behavioral aspect of learners' AELL and teachers' CF was assessed. The results are illustrated in "Table 2". As it is indicated, there is a positive correlation between Iranian EFL teachers' CF and 
behavioral aspect of their students' AELL ( $r=.27, p<.05)$. Therefore, the higher Iranian EFL teachers' $C F$, the more positive behavioral attitudes have Iranian EFL learners.

Table 2: Pearson Correlations of EFL Teachers' CF and EFL Learners' Attitude (Behavioral)

\begin{tabular}{llcc}
\hline & & cognitive.flexiblity & BEHAVIORAL \\
\hline \multirow{3}{*}{ cognitive.flexiblity } & Pearson Correlation & 1 & $.276^{*+}$ \\
& Sig. (2-tailed) & 357 & .000 \\
& $\mathrm{~N}$ & $.276^{*+}$ & 357 \\
& Pearson Correlation & .000 & 1 \\
BEHAVIORAL & Sig. (2-tailed) & 357 & 357 \\
& $\mathrm{~N}$ & & \\
\hline
\end{tabular}

**. Correlation is significant at the 0.01 level (2-tailed).

Then, the correlation between Iranian EFL learners' cognitive aspect of AELL and Iranian EFL teachers' CF was assessed. The results are observed in "Table 3". Based on the results, a positive correlation was revealed between Iranian EFL teachers' CF and their students' cognitive aspect of attitude $(r=.23, p<.05)$. So, the higher Iranian EFL teachers' CF, the more positive cognitive attitudes have Iranian EFL learners.

Table 3: Pearson Correlations of EFL Teachers' CF and EFL Learners' Attitude (Cognitive)

\begin{tabular}{llcc}
\hline & & cognitive.flexiblity & COGNITIVE \\
\hline \multirow{2}{*}{ cognitive.flexiblity } & Pearson Correlation & 1 & $.234^{*+*}$ \\
& Sig. (2-tailed) & & .000 \\
& $\mathrm{~N}$ & 357 & 357 \\
\multirow{3}{*}{ COGNITIVE } & Pearson Correlation & $.234^{*+}$ & 1 \\
& Sig. (2-tailed) & .000 & \\
& $\mathrm{~N}$ & 357 & 357 \\
\hline
\end{tabular}

**. Correlation is significant at the 0.01 level (2-tailed).

Finally, the correlation between Iranian EFL learners' emotional aspect of AELL and Iranian EFL teachers' CF was assessed. "Table 4" depicts the results of this analysis. As it shows, there is a positive correlation between Iranian EFL teachers' CF and their students' emotional aspect of attitude $(r=.44, p<.05)$. Hence, the higher Iranian EFL teachers' cognitive flexibility, the more positive emotional attitudes have Iranian EFL learners.

Table 4: Pearson Correlations of EFL Teachers' CF and EFL Learners' Attitude (Emotional)

\begin{tabular}{llcc}
\hline & & cognitive.flexiblity & EMOTIONAL \\
\hline \multirow{2}{*}{ cognitive.flexiblity } & Pearson Correlation & 1 & $.448^{* *}$ \\
& Sig. (2-tailed) & 357 & .000 \\
& $\mathrm{~N}$ & $.448^{* *}$ & 357 \\
\multirow{2}{*}{ EMOTIONAL } & Pearson Correlation & .000 & 1 \\
& Sig. (2-tailed) & 357 & 357 \\
\hline${ }^{*}$. Correlation is significant at the 0.01 level (2-tailed). & &
\end{tabular}

To summarize, the results of running Pearson Product-Moment Correlation indicated that Iranian EFL teachers' CF was related to all subscales of Iranian EFL learners' attitudes towards English language learning including behavioral, cognitive and emotional domains. However, Iranian EFL teachers' CF had the highest correlation with emotional aspect of Iranian EFL learners' AELL. Then, the behavioral aspect of AELL came second and cognitive aspect of Iranian EFL learners' attitudes indicated the lowest amount of correlation with Iranian EFL teachers' CF compared with the other two aspects.

As it was stated, the goal of this investigation was to explore if there is any significant relationship between Iranian EFL teachers' CF and Iranian EFL learners' attitudes. While different researches in issues concerning CF and AELL have been conducted, there is no known published information on the relationship between these variables.

Based on the results of this study, positive correlations were found between Iranian EFL teachers' CF and their 
students' AELL in terms of emotional, behavioral and cognitive aspects. In line with this finding, other researchers found relationships between CF and some other psychological concepts. E.g. positive correlation between CF and behavioral flexibility, interaction involvement including perceptiveness, responsiveness and attentiveness (Martin and Rubin, 1995); positive correlation between CF and responsiveness, assertiveness, self-efficacy and communication competence (Martin and Anderson, 1998); positive correlation between CF and conversational sensitivity (Chesebro and Martin, 2003); and positive relationships between CF; self-compassion and intellectual flexibility (Martin et al., 2011).

\section{Conclusion}

The purpose of the present study was to explore the relationship between Iranian EFL teachers' cognitive flexibility and their students' attitudes towards English language learning. Based on the findings of this investigation along with the outcomes of other probes in the field of English language teaching and learning, some conclusions can be drawn as follows.

It has been accepted that learners' attitudes as affective language learning components highly influence its success or failure. Several researchers assert that positive attitudes have beneficial impacts on language learning and facilitate it by enhancing students' motivation and leading them to achieve educational goals. (Gardner, 1985 \& Zainol Abidin, et al., 2012). Tseng (2013) believes teachers should notice that students' negative attitudes can be replaced by positive ones and this is partly the duty of the teachers. Accordingly, there is a need for all EFL teachers to consider their students' attitudes, needs and emotions before their cognitive abilities and try to promote their positive attitudes towards language learning. In this way, EFL learners enjoy learning the target language and involve in language learning process so they can achieve cognitive capabilities.

There are various factors such as EFL teachers' characteristics which contribute to the development of EFL learners' positive attitudes. CF was one of such personality traits examined in this investigation. Hence, this study aimed to highlight the significance of CF and to explore the relationship between Iranian EFL teachers' CF and their students' attitudes towards English language learning in terms of behavioral, cognitive and emotional aspects.

The results of this study provide researchers, EFL teachers, etc. with a better insight regarding the significant role of CF as a stimulus applied for promoting EFL learners' positive AELL. Based on the found correlations between the examined variables of this study it can be concluded that Iranian EFL teachers' high CF will result in developing Iranian EFL learners' positive attitudes particularly in emotional dimension and this will lead to promoting EFL learners' language learning success.

Regarding the importance of CF, as this study suggests, the complexities of everyday life which is full of novel and unexpected situations reinforce the need to be cognitively flexible. Since in this post-modern world, things change quickly and new techniques are introduced regularly, EFL teachers as the members of this modern community are required to adapt to the unpredictable changes to improve teaching and learning in different settings.

This study offers teachers to notice that they face different students in various contexts. They should consider individuality as an important factor in their teaching process. E.g. the methods they choose for extrovert students should differ from introvert ones. The same seems true for different educational settings, etc. Consequently, by noticing the findings of this study, EFL teachers can gain a thorough insight about the benefits of CF as an essential component of communication competence and as a necessary characteristic for all teachers in general but EFL teachers in particular which help them in this regard to replace traditional rigidity in their teaching methods with flexibility to cope with situational demands.

Additionally, the results of this study can provide hints for all those who involve in EFL teaching and learning to think about how to integrate CF into EFL educational policy as well as how to promote it as a vital mental capability in EFL teachers and learners. As it was proposed by Moreira (1999), Duffy and Jonassen (1992) and Spiro et al. (1988), the use of Cognitive Flexibility Hypertexts designed based on CFT principles is a means to integrate CF into education as well as an effective way to improve CF of EFL teachers and learners. CFHs are computer-based texts which provide a multifaceted, contextualized and flexible structure of material presentations which enable teachers and learners to incorporate new information and integrate it with preexisting schemata to handle novel situations. Therefore, as the results of this study suggests, because of the high correlation between EFL teachers' CF and EFL learners' positive AELL, there is a need to incorporate the ways to develop EFL teachers' CF into teacher education programs and inservice training. Moreover, all those who involve in EFL teaching and learning can think about designing appropriate CFHs which can contribute to achieve the aim of developing EFL teachers' CF.

Moreover, the significant correlations which were found between Iranian EFL teachers' CF and Iranian EFL learners' AELL may lead researchers and practitioners to think about the probable relationships between these teacher- 
related variables as well as other EFL teachers' capabilities and student-related affective domains.

\section{References}

Abdol Latif, L., Fadzil, M., BAhroom, R., Mohamad, W., \& Ng, M. S. (2011, March). The Role of Motivation, Attitude, Anxiety and Instrumental Orientation in Influencing Learners' Performance in English as a Second Language in OUM. In Global Learn (Vol. 2011, No. 1, pp. 1659-1668). Retrieved from: http://eprints.oum.edu.my/565/

Ajzen, I. (2005). Attitudes, personality, and behavior. McGraw-Hill International.

Alavinia, P., \& Salmasi, M. (2012). On the Correlation between Iranian EFL Learners'

Shyness Level and their Attitudes toward Language Learning. Research on Humanities and Social Sciences, 2(9), 91-102.

Al-Tamimi, A. \& Shuib, M. (2009). Motivation and attitudes towards learning English: A

study of petroleum engineering undergraduates At Hadhramout University Of Sciences And Technology. GEMA Online Journal of Language Studies, 9(2). Retrieved from: http://www.ukm.my/ppbl/Gema/pp\%2029_55.pdf

Boger-Mehall, S. R. (1996). Cognitive flexibility theory: Implications for teaching and teacher education. In Society for Information Technology \& Teacher Education International Conference (Vol. 1996, No. 1, pp. 991-993).

Brown, D. H. (2007). Principles of language learning and teaching. (5th Eds.). Pearson: Longman.

Carvalho, A. A., \& Moreira, A. (2005). Criss-crossing Cognitive Flexibility Theory based research in Portugal: an overview. Interactive Educational Multimedia, 11, 1-26. Retrieved from: http://www.ub.es/multimedialiem

Cayanus, J. L. (2005). Students' Propensity to Ask Questions: Do Cognitive Flexibility, Teacher Self-Disclosure, Student Motives to Communicate, and Affective Learning Influence Question Asking in the Classroom? PH.D Dissertation. West Virginia University. Retrieved from: http://wvuscholar.wvu.edu:8881//exlibris/dtt/d3_1

Chesebro, J. L., \& Martin, M. M. (2003). The relationship between conversational sensitivity, cognitive flexibility, verbal aggressiveness and indirect interpersonal aggressiveness. Communication Research Reports, 20(2), 143-150.

Deak, G O (2003). "The development of cognitive flexibility and language abilities". Advances in Child Development and Behavior 31: 271-327. PMID 14528664.

Dennis, J. P., \& Vander Wal, J. S. (2010). The cognitive flexibility inventory: Instrument development and estimates of reliability and validity. Cognitive therapy and research, 34(3), 241-253.

Duffy, T. M., \& Jonassen, D. H. (Eds.). (1992). Constructivism and the technology of instruction: A conversation. Psychology Press. Retrieved from: http://samples.sainsburysebooks.co.uk/9781136612282_sample_502793.pdf

Elen, J., Stahl, E., Bromme, R., \& Clarebout, G. (2011). Links between Beliefs and Cognitive Flexibility. Springer.

Gardner, R. C. (1985). Social Psychology and Second Language Learning: The Role of Attitudes and Motivation. London: Edward Arnold.

Hosseini, S. B., \& Pourmandnia, D. (2013). Language learners' attitudes and beliefs: Brief review of the related literature and frameworks. International Journal on New Trends in Education and Their Implications.

Kara, A. (2009). The Effect of a 'Learning Theories' Unit on Students' Attitudes towards Learning. Australian Journal of Teacher Education, 34(3), 100-113. [Online] Available: http://ro.ecu.edu.au/ajte/vol34/iss3/5 (August 10, 2011)

Krejcie, R. V., \& Morgan, D. W. (1970). Determining sample size for research activities. Educ Psychol Meas.

Martin, M. M., \& Anderson, C. M. (1998). The Cognitive Flexibility Scale: Three validity studies. Communication Reports, 11, 1-9.

Martin, M. M., Anderson, C. M., \& Thweatt, K. S. (1998). Individuals' perceptions of their communication behaviors: A validity study of the relationship between the Cognitive Flexibility Scale and the Communication Flexibility Scale with aggressive communication traits. Journal of Social Behavior and Personality, 13, 531-540.

Martin, M M; Rubin, R B (1995). "A new measure of cognitive flexibility". Psychological Reports 76: 623-626. doi:10.2466/pr0.1995.76. 2.623. http://www.amsciepub.com/doi/abs/10.2466/pr0.1995.76.2.623

Martin, M. M., Staggers, S. M., \& Anderson, C. M. (2011). The relationships between cognitive flexibility with dogmatism, intellectual flexibility, preference for consistency, and self-compassion. Communication Research Reports, 28(3), 275-280.

Moreira, A. (1999). Teacher Education in EFL and the Development of Cognitive Flexibility.

Lisbon, TNTEE. Acedido em http://thtee. umu. se/lisboa/papers/abstractportugal. htm/\# moreira. Retrieved from: http://findpdf.net/reader/ Teacher-Education-in-EFL-and-the-Development-of-Cognitive-Flexibility.html

Parks, M. R. (1994). Communication competence and interpersonal control. In M. L. Knapp \& G. R. Miller (Eds.), Handbook of interpersonal communication (pp. 589-620). Beverly Hills, CA: Sage.

Richards, J. C., Platt, J., \& Platt, H. (1992). Longman dictionary of language teaching and applied linguistics.

Soleimani, H., \& Hanafi, S. (2013). Iranian Medical Students' Attitudes towards English Language Learning. International Research Journal of Applied and Basic Sciences. 4 (12):3816-3823. Retrieved from: http://www.irjabs.com/files_site/paperlist/r_1375_ 130914103018.pdf

Spiro, R.; Coulson, R.; Feltovich, P. \& Anderson, D. (1988) Cognitive flexibility: Advanced knowledge acquisition ill-structured domains. Proc. of the Tenth Annual Conference of Cognitive Science Society, Hillsdale, NJ: Erlbaum, 375-383.

Spiro, R.J., Feltovich, P.J., Jacobson, M.J., \& Coulson, R.L. (1992). Cognitive Flexibility,

Constructivism, and Hypertext: Random Access Instruction for Advanced Knowledge Acquisition in III-Structured Domains. In Duffy, T. M., \& Jonassen, D. H. (Eds.), Constructivism and the technology of instruction: A conversation (pp.121-128). Hillsdale, NJ: Lawrence Erlbaum Associates Publishers. 
Spiro, R.J. and Jehng, J. (1990) Cognitive Flexibility and Hypertext: Theory and Technology for Nonlinear and Multidimensional Traversal of Complex Subject Matter. In Nix, D. and Spiro, R. (1990) (eds.) Cognition, Education and Multimedia: Exploring Ideas in High Technology. Hillsdale, Lawrence Erlbaum Associates, Publishers.

Spiro, R., Vispoel, W.p., Schmitz, J.G., Samarapungavan, A. e Boerger, A.E. (1987).

Knowledge Acquisition for Application: Cognitive Flexibility and Transfer in Complex Content Domains. In B.C. Britton e S. M. Glynn (eds.), Executive Control in Processes in Reading. New Jersey: Lawrence Erlbaum Associates, 177-199.

Stronge, J. H. (2007). Qualities of effective teachers. ASCD.

Tabatabaei, O., \& Bandari, M. M. (2012). Iranian EFL learners' attitudes towards the use of computer-mediated PowerPoint presentations. Theory and Practice in Language Studies, 2(2), 214-223. Retrieved from: http://ojs.academypublisher.com/ index. php/tpls/article/view/tpls0202214223

Teimourtash, M. (2013). Flexible Teachers vs. Rigid Learners: "Opportunities Lost \& Found in Iranian EFL Context". Journal of Nature Inspired Computing, 1(1), 14-18. Retrieved from: http://worldsciencepublisher.org/journals/ index.php/JNIC/article/view/1265

Tseng, M. C. (2013). The Relationship between Attitudes toward Foreign Culture and English Proficiency Level in Taiwanese Students of English as a Foreign Language. Studies in English Language Teaching, 1 (2), p264. Retrieved from: www.scholink.org/ojs/index. php/selt

Zainol Abidin, M. J., Pour-Mohammadi, M., \& Alzwari, H. (2012). EFL students' attitudes towards learning English language: The case of Libyan secondary school students. Asian social science, 8(2), p119. 